\title{
Supplement Article
}

\section{A Diagnostic Marker to Discriminate Childhood Apraxia of Speech From Speech Delay: III. Theoretical Coherence of the Pause Marker with Speech Processing Deficits in Childhood Apraxia of Speech}

\author{
Lawrence D. Shriberg, ${ }^{\text {a }}$ Edythe A. Strand, ${ }^{\text {b }}$ Marios Fourakis, ${ }^{\text {a Kathy J. Jakielski, }}{ }^{\mathrm{c}}$ \\ Sheryl D. Hall, ${ }^{a}$ Heather B. Karlsson, ${ }^{a}$ Heather L. Mabie, ${ }^{a}$ Jane L. McSweeny, ${ }^{a}$ \\ Christie M. Tilkens, ${ }^{a}$ and David L. Wilson ${ }^{a}$
}

\begin{abstract}
Purpose: Previous articles in this supplement described rationale for and development of the pause marker (PM), a diagnostic marker of childhood apraxia of speech (CAS), and studies supporting its validity and reliability. The present article assesses the theoretical coherence of the PM with speech processing deficits in CAS.

Method: PM and other scores were obtained for 264 participants in 6 groups: CAS in idiopathic, neurogenetic, and complex neurodevelopmental disorders; adult-onset apraxia of speech (AAS) consequent to stroke and primary progressive apraxia of speech; and idiopathic speech delay.

Results: Participants with CAS and AAS had significantly lower scores than typically speaking reference participants
\end{abstract}

and speech delay controls on measures posited to assess representational and transcoding processes. Representational deficits differed between CAS and AAS groups, with support for both underspecified linguistic representations and memory/access deficits in CAS, but for only the latter in AAS. CAS-AAS similarities in the age-sex standardized percentages of occurrence of the most frequent type of inappropriate pauses (abrupt) and significant differences in the standardized occurrence of appropriate pauses were consistent with speech processing findings.

Conclusions: Results support the hypotheses of core representational and transcoding speech processing deficits in CAS and theoretical coherence of the PM's pause-speech elements with these deficits.

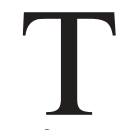
he second article in this series (PM II; Shriberg et al., 2017b) described rationale and validity support for a diagnostic marker of childhood apraxia of speech (CAS) termed the pause marker (PM), and a following article (PM IV; Shriberg et al., 2017c) reports validity support for an ordinal severity scale for the PM termed the pause marker index (PMI). The present article

\footnotetext{
${ }^{\mathrm{a}}$ Waisman Center, University of Wisconsin-Madison

${ }^{\mathrm{b}}$ Department of Neurology, Mayo Clinic-Rochester, NY

${ }^{\mathrm{c}}$ Department of Communication Sciences and Disorders, Augustana College, Rock Island, IL

Correspondence to Lawrence D. Shriberg: shriberg@waisman.wisc.edu

Editor and Associate Editor: Julie Liss

Received August 24, 2015

Revision received April 12, 2016

Accepted August 21, 2016

https://doi.org/10.1044/2016_JSLHR-S-15-0298
}

assesses the theoretical coherence of the PM with speech processing deficits in CAS.

It is useful to reproduce Figure 1 from the first article in this series (PM I; Shriberg et al., 2017a), which will be referenced throughout the present article. Figure 1, the research framework for the PM termed the Speech Disorders Classification System (SDCS), includes a sevenelement generic representation of speech processing stages. Recall (PM I; Shriberg et al., 2017a) that Figure 1 is the finalized version of the SDCS with the exception of some updates at Level III and Level IV that are not pertinent in the present context (Shriberg, Strand, \& Mabie, 2017). The following sections describe relevant terms and concepts in CAS research, followed by brief literature overviews of research addressing two hypotheses about speech processing deficits in CAS. 


\section{Terms and Concepts}

There is a need in CAS research for explicit descriptiveexplanatory terms that link speech processing deficits in CAS to behavioral signs of those deficits. We use substrates to denote genomic and neural origins of signs of CAS (see Figure 1, Level I), deficits to denote speech processing origins proposed to underlie signs of CAS (Level II), and marker to denote a single- or multisign behavioral (Level IV) or neural (Level I) measure validated as conclusively sensitive to and specific for CAS.

The primary need in CAS research is explicit criteria for one or more speech processing constraints posited to be a core CAS deficit. We define a core CAS processing deficit as one that underlies the onset and persistence of CAS. As addressed later, we specifically propose that a core CAS speech processing deficit meets four criteria: It must be present in participants with CAS (a) in all etiological contexts, (b) at the earliest and latest stages of expression of CAS, (c) at all levels of severity of expression, and (d) without moderation or mediation by any other speech processing deficit.

\section{Representational and Transcoding Processing Deficits in CAS}

There is consensus in both the CAS and adult-onset apraxia of speech (AAS) literature that the core deficit in apraxia of speech is imprecise and unstable transcoding of linguistic representations of segmental features, phonemes, syllables, words, and lexical stress to motor plans and programs for manifest speech. As shown in Figure 1, there is also general consensus that deficits in feedforward and feedback processes are loci of processing deficits in apraxia of speech, with more support for feedforward deficits (see next section).

There is considerably less agreement in both the CAS and AAS literatures on whether each disorder also includes deficits in representational processes - specifically, deficits in the precision and stability of encoding appropriately specified phonological representations of speech domains and/or deficits in memory constraining the storage and/or retrieval of representations (e.g., Chilosi et al., 2015; Nijland, Terband, \& Maassen, 2015; Shriberg, Lohmeier, Strand, \& Jakielski, 2012). Moreover, if deficits in appropriate specification and/or in the storage/retrieval of representations are documented in CAS, a significant question for theory and treatment is whether they are core or corollary deficits in the CAS phenotype. As proposed previously, a core deficit would be required to meet three criteria that are not moderated or mediated by individual speaker characteristics. A corollary deficit, in contrast, could be a consequence of developmental or other moderating and mediating factors (Bishop, 1997).

Comprehensive reviews of research findings addressing the hypotheses of core or corollary representational, transcoding, and feedforward/feedback deficits in CAS are beyond the scope of the present article. The available CAS literature reviews in monographs, book chapters, and research articles and presentations have typically been organized by discipline (e.g., genomics, speech motor control), measurement

Figure 1. The Speech Disorders Classification System (SDCS).

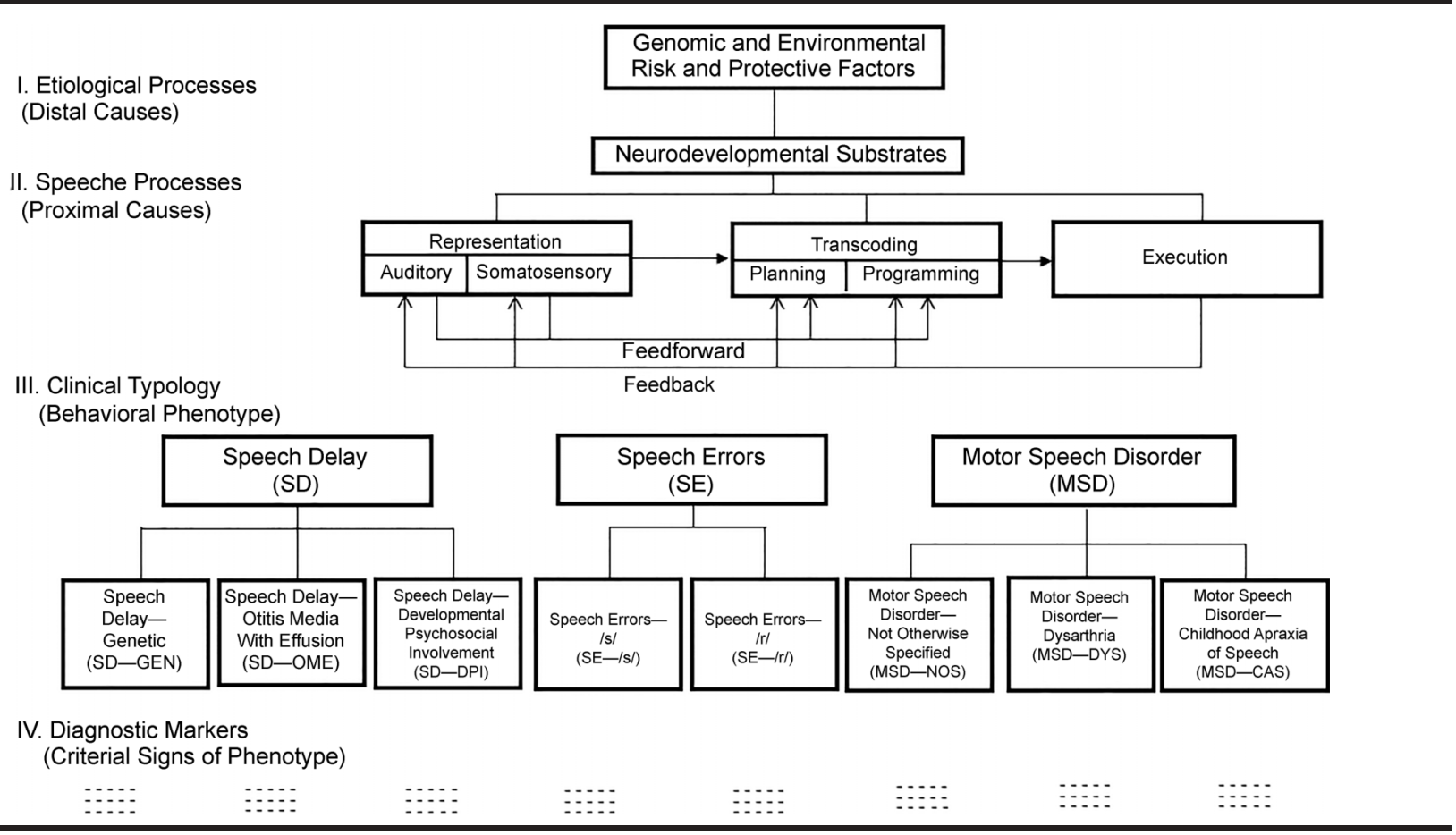


modality (e.g., neuroimaging, electrophysiology, kinematic methods), or by putative clinical signs (e.g., inappropriate prosody, a sequencing deficit). PM I and PM II include citations to relevant literature reviews, most of which are organized in one of these ways.

Table 1 is a sample of 20 findings from 17 CAS studies organized by speech processing deficit, with 12 findings that address or report findings relevant to representational deficits and eight findings that address or report findings relevant to transcoding deficits. Studies using findings from feedback/feedforward processes are included with either representational or transcoding studies depending on which CAS speech process deficit they inform. As indicated in the column headings, the 20 entries in Table 1 were selected to sample the array of measurement approaches and speech processing deficits posited in CAS research. Space constraints prohibit including samples of studies from basic research literatures increasingly relevant to CAS, including gene expression research, research on the functional biology of nonhuman vocal learners, and paleobiological studies of the evolution of speech and language (e.g., Mozzi et al., 2016).

\section{Representational Deficits in CAS}

As indicated previously, the hypothesis of a core representational deficit in speakers with apraxia of speech posits that the origins of the speech, prosody, and voice signs of CAS are either in underspecified (weak, imprecise) representations of segmental and suprasegmental parameters or in memory capacity and processing deficits constraining storage capacity and timely access to representations. For the former, as shown in Level II of Figure 1, deficits in constructs such as awareness, attention, acuity, and discrimination are proposed as possible sources of underspecified representations of features, phonemes, syllables, words, or lexical stress assignment. Memory and associated cognitive deficits are not represented in the generic framework in Figure 1 because they are potential constraints on the products of all stages of speech processing, including the strength, precision, or stability of representational, transcoding, feedforward, execution, and feedback processes.

The first section of Table 1 includes a sample of older and relatively more recent findings addressing or consistent with the hypothesis of core CAS deficits in representational processes. Using different neuroimaging modalities, findings from the first three sample studies in Table 1 support the hypothesis of deficits in representational processing associated with the functional neurobiology of speech. The sample entry in Table 1 for research using neurocomputational modeling supports processing deficits in auditory and somatosensory feedforward controls as sources of both underspecified representations and motor programming deficits in CAS. The remaining eight studies using behavioral methods support the hypothesis of representational deficits in CAS, including auditory-perceptual and memory constraints that affect the precision (i.e., accuracy, strength, and weakness) of underlying representations in different linguistic domains and storage of and access to representations. Again, space constraints prohibit discussion of the implications for theory of each of the Table 1 sample studies of deficits in representational processes in CAS. As illustrated by these studies, the CAS literature includes an array of findings interpreted as support for core deficits in representational processes. There are also parental surveys (e.g., Teverovsky, Bickel, \& Feldman, 2009) and anecdotal accounts in books, book chapters, and on websites describing CAS deficits in a number of cognitive-linguistic, affective, and general health domains.

\section{Transcoding Deficits in CAS}

The second section of Table 1 includes a sample of studies addressing or consistent with the hypothesis of core CAS deficits in transcoding processes. As with the Table 1 entries for representational studies, most CAS studies addressing or consistent with the hypotheses of core transcoding deficits include a relatively small number of participants selected using diverse inclusionary and exclusionary criteria, and few studies have been systematically crossvalidated. It is of note that although control groups have included participants with both typically developing speech and speech delay (SD), few published studies have included participants with both CAS and AAS. Notwithstanding these and other design limitations, support for both representational and transcoding deficits in CAS in the current century is increasingly based on sensitive, reliable, and efficient instrumental measures.

\section{Statement of the Problem}

The availability of the several etiologically and demographically diverse databases assembled in the development of the PM and the PMI (see PM IV; Shriberg et al., 2017c) provided the opportunity to address the second of the three questions posed in this series:

Question 2: Do findings from the PM and other measures support the hypothesis of core representational and transcoding deficits in CAS, and is the PM theoretically coherent with those deficits?

We first attempt to clarify whether CAS is best understood as a motor speech disorder (MSD) only, or alternatively, if representational (encoding, memory, language) deficits are part of the core pathobiological phenotype, with implications for assessment, treatment, and prevention. As discussed presently, the descriptive behavioral methods of the present study did not provide a means to address the hypothesis of core feedforward and/or feedback deficits in CAS. Last, we address the coherence of the PM to the speech processing findings by examining statistically and theoretically informative similarities and differences in the pause and speech elements of the PM in participants with CAS compared to participants with AAS.

\section{Method \\ Participants}

Table 2 includes descriptive information for four research groups totaling 310 participants: 37 participants, 
Table 1. A sample of neuroimaging, neurocomputational modeling, and behavioral assessment findings in childhood apraxia of speech (CAS) consistent with the hypothesis of core precision and stability deficits in phonological representations (first 12 findings) and transcoding (last eight findings).

\begin{tabular}{|c|c|c|c|c|c|}
\hline $\begin{array}{l}\text { Processing } \\
\text { domain }\end{array}$ & $\begin{array}{l}\text { Measurement } \\
\text { domain }\end{array}$ & Processing deficit & Measurement & Finding & Reference \\
\hline \multirow[t]{9}{*}{ Representational } & \multirow[t]{3}{*}{$\begin{array}{l}\text { Neuroimaging } \\
\text { modalities }\end{array}$} & $\begin{array}{l}\text { Auditory perceptual } \\
\text { processes }\end{array}$ & $\begin{array}{l}\text { Cortical thickness maps, } \\
\text { including regions of } \\
\text { interest that subserve } \\
\text { auditory perceptual } \\
\text { processes }\end{array}$ & $\begin{array}{l}11 \text { children with idiopathic apraxia had } \\
\text { significantly thicker left posterior } \\
\text { supramarginal gyri than controls. After } \\
\text { speech treatment, } 8 \text { of } 9 \text { children with } \\
\text { CAS had significant thinning in the } \\
\text { posterior superior temporal gyrus } \\
\text { compared to } 1 \text { of } 3 \text { controls. }\end{array}$ & Kadis et al. (2013) \\
\hline & & $\begin{array}{l}\text { Phonological } \\
\text { representations }\end{array}$ & $\begin{array}{l}\text { Electroencephalograph; } \\
\text { mismatched negativity }\end{array}$ & $\begin{array}{l}5 \text { children with CAS were inferred to have } \\
\text { overspecified underlying phonological } \\
\text { representations. }\end{array}$ & $\begin{array}{l}\text { Froud and Khamis- } \\
\text { Dakwar (2012) }\end{array}$ \\
\hline & & $\begin{array}{l}\text { Phonological retrieval } \\
\text { and syllabification }\end{array}$ & $\begin{array}{l}\text { Electroencephalograph; } \\
\text { event-related potentials }\end{array}$ & $\begin{array}{l}8 \text { children with CAS differed from } \\
\text { controls on neurophysiological findings } \\
\text { supporting a phonological deficit, } \\
\text { particularly in constructing complex } \\
\text { phonological word forms. }\end{array}$ & Preston et al. (2014) \\
\hline & $\begin{array}{l}\text { Neurocomputational } \\
\text { modeling }\end{array}$ & $\begin{array}{l}\text { Auditory and } \\
\text { somatosensory } \\
\text { feedforward control }\end{array}$ & $\begin{array}{l}\text { Simulation of auditory } \\
\text { processing and motor } \\
\text { programming deficits }\end{array}$ & $\begin{array}{l}\text { Findings were interpreted as support for } \\
\text { the hypothesis that CAS includes both } \\
\text { underspecified representations and } \\
\text { motor programming deficits. }\end{array}$ & Terband et al. (2014) \\
\hline & \multirow[t]{5}{*}{$\begin{array}{l}\text { Behavioral } \\
\text { assessment }\end{array}$} & $\begin{array}{l}\text { Auditory perceptual } \\
\text { processes }\end{array}$ & $\begin{array}{l}\text { Resynthesized and } \\
\text { synthesized } \\
\text { monosyllabic word } \\
\text { tasks differing in } \\
\text { place of articulation } \\
\text { of the initial voiced } \\
\text { stop consonant }\end{array}$ & $\begin{array}{l}17 \text { children with CAS had lower } \\
\text { identification and discrimination } \\
\text { performance than controls. }\end{array}$ & Groenen et al. (1996) \\
\hline & & $\begin{array}{l}\text { Auditory perceptual } \\
\text { processes }\end{array}$ & $\begin{array}{l}\text { Resynthesized vowel } \\
\text { continual tasks }\end{array}$ & $\begin{array}{l}11 \text { children with CAS had poorer } \\
\text { identification and discrimination } \\
\text { performance than controls, } \\
\text { supporting subtle (subclinical) } \\
\text { auditory processing deficits. }\end{array}$ & Maassen et al. (2003) \\
\hline & & $\begin{array}{l}\text { Phonological } \\
\text { awareness }\end{array}$ & $\begin{array}{l}\text { Phonological awareness } \\
\text { tasks }\end{array}$ & $\begin{array}{l}12 \text { children with CAS had lower } \\
\text { phonological awareness scores } \\
\text { than children with typical speech } \\
\text { development and children with } \\
\text { inconsistent speech disorder. }\end{array}$ & McNeill et al. (2009) \\
\hline & & $\begin{array}{l}\text { Phonological } \\
\text { representations }\end{array}$ & $\begin{array}{l}\text { Spontaneous and forced } \\
\text { choice rhyming tasks }\end{array}$ & $\begin{array}{l}4 \text { children with CAS had a severe } \\
\text { rhyming deficit compared to children } \\
\text { with typical speech development. }\end{array}$ & Marion et al. (1993) \\
\hline & & $\begin{array}{l}\text { Phonological encoding } \\
\text { and memory }\end{array}$ & $\begin{array}{l}\text { Encoding and memory } \\
\text { subscales of a } \\
\text { nonsense syllable } \\
\text { repetition task }\end{array}$ & $\begin{array}{l}40 \text { participants with CAS had significantly } \\
\text { lower encoding and memory scores } \\
\text { than children with typical speech } \\
\text { development and children with } \\
\text { speech delay. }\end{array}$ & Shriberg et al. (2012) \\
\hline
\end{tabular}


Table 1. (Continued).

\begin{tabular}{|c|c|c|c|c|c|}
\hline $\begin{array}{l}\text { Processing } \\
\text { domain }\end{array}$ & $\begin{array}{l}\text { Measurement } \\
\text { domain }\end{array}$ & Processing deficit & Measurement & Finding & Reference \\
\hline \multirow{7}{*}{ Transcoding } & & $\begin{array}{l}\text { Representations of } \\
\text { syllables }\end{array}$ & $\begin{array}{l}\text { Tasks requiring participants } \\
\text { to identify the number } \\
\text { of syllables in words, } \\
\text { judge intrasyllabic sound } \\
\text { positions, and construct } \\
\text { syllable shapes within } \\
\text { monosyllabic frames }\end{array}$ & $\begin{array}{l}3 \text { children with CAS had lower scores } \\
\text { than typically speaking children on } \\
\text { three tasks that assessed ability to } \\
\text { perceive and access representations } \\
\text { of syllables. }\end{array}$ & $\begin{array}{l}\text { Marquardt et al. } \\
\text { (2002) }\end{array}$ \\
\hline & & $\begin{array}{l}\text { Sequencing speech } \\
\text { and nonverbal } \\
\text { sequential functions }\end{array}$ & $\begin{array}{l}\text { Tasks requiring participants } \\
\text { to complete simple and } \\
\text { complex sensorimotor } \\
\text { and sequential memory } \\
\text { functions on two occasions } \\
\text { within } 15 \text { months }\end{array}$ & $\begin{array}{l}17 \text { children with CAS had lower scores } \\
\text { on the sequential memory and complex } \\
\text { sensorimotor tasks than typically } \\
\text { developing children, with significant } \\
\text { correlations between their cognitive } \\
\text { scores and their speech impairment. }\end{array}$ & Nijland et al. (2015) \\
\hline & & Feedforward/feedback & $\begin{array}{l}\text { Conversational speech } \\
\text { samples }\end{array}$ & $\begin{array}{l}19 \text { children with CAS did not have evident } \\
\text { articulatory struggle (groping) and did } \\
\text { not attempt to correct their speech } \\
\text { errors, interpreted as support for deficits } \\
\text { in underlying linguistic representations. }\end{array}$ & Shriberg et al. (1997) \\
\hline & $\begin{array}{l}\text { Neuroimaging } \\
\text { modalities }\end{array}$ & Planning/programming & $\begin{array}{l}\text { Electroencephalograph; } \\
\text { event-related potentials }\end{array}$ & $\begin{array}{l}8 \text { children with CAS had different } \\
\text { electrophysiological activity than } \\
\text { controls over the right hemisphere in } \\
\text { the later stages of speech preparation. }\end{array}$ & Preston et al. (2014) \\
\hline & $\begin{array}{l}\text { Neurocomputational } \\
\text { modeling }\end{array}$ & $\begin{array}{l}\text { Auditory and } \\
\text { somatosensory } \\
\text { feedforward control }\end{array}$ & $\begin{array}{l}\text { Simulation of auditory } \\
\text { processing and motor } \\
\text { programming deficits }\end{array}$ & $\begin{array}{l}\text { Findings interpreted as support for } \\
\text { hypothesis that CAS includes both } \\
\text { underspecified representations } \\
\text { and motor programming deficits. }\end{array}$ & Terband et al. (2014) \\
\hline & \multirow[t]{2}{*}{$\begin{array}{l}\text { Behavioral } \\
\text { assessment }\end{array}$} & $\begin{array}{l}\text { Planning/programming; } \\
\text { coordination of } \\
\text { syllabic gestures }\end{array}$ & Acoustic analyses & $\begin{array}{l}19 \text { children with CAS had more variable } \\
\text { and deviant coarticulation patterns } \\
\text { between and within syllables than } \\
\text { controls, interpreted as support for } \\
\text { delays in coordination of syllabic } \\
\text { gestures. }\end{array}$ & Maassen et al. (1997) \\
\hline & & $\begin{array}{l}\text { Planning/programming; } \\
\text { coarticulatory } \\
\text { cohesion }\end{array}$ & $\begin{array}{l}\text { Acoustic analyses; } \\
\text { F2 ratios }\end{array}$ & $\begin{array}{l}9 \text { children with CAS had more variable } \\
\text { intra- and intersyllabic anticipatory } \\
\text { coarticulation than typically speaking } \\
\text { children and adult women. }\end{array}$ & Nijland et al. (2002) \\
\hline & & & & & (table continues) \\
\hline
\end{tabular}


Table 1. (Continued).

\begin{tabular}{|c|c|c|c|c|c|}
\hline $\begin{array}{l}\text { Processing } \\
\text { domain }\end{array}$ & $\begin{array}{l}\text { Measurement } \\
\text { domain }\end{array}$ & Processing deficit & Measurement & Finding & Reference \\
\hline & & Planning/programming & $\begin{array}{l}\text { Transcription and acoustic } \\
\text { analyses of vowels and } \\
\text { diphthongs produced } \\
\text { in monosyllabic and } \\
\text { multisyllabic real words } \\
\text { and pseudowords }\end{array}$ & $\begin{array}{l}3 \text { children with CAS had comparable error } \\
\text { percentages and imprecision in real } \\
\text { and pseudowords, consistent with a } \\
\text { motor speech deficit at the stage of } \\
\text { planning/programming. }\end{array}$ & Blech et al. (2007) \\
\hline & & $\begin{array}{l}\text { Planning/programming; } \\
\text { movement variability }\end{array}$ & $\begin{array}{l}\text { Kinematics; motion capture } \\
\text { system }\end{array}$ & $\begin{array}{l}11 \text { children with CAS had significantly } \\
\text { higher movement variability than children } \\
\text { with typical speech development and } \\
\text { children with SD. }\end{array}$ & Grigos et al. (2015) \\
\hline & & $\begin{array}{l}\text { Planning/programming } \\
\text { and/or feedforward/ } \\
\text { processes }\end{array}$ & $\begin{array}{l}\text { Encoding and memory } \\
\text { subscales of a nonsense } \\
\text { syllable repetition task }\end{array}$ & $\begin{array}{l}40 \text { participants with CAS had a } \\
\text { significantly higher percentage of } \\
\text { addition/complication errors (e.g., } \\
\text { on/off glides) than controls with SD. }\end{array}$ & Shriberg et al. (2012) \\
\hline & & Feedforward processes & $\begin{array}{l}\text { Auditory masking paradigm; } \\
\text { VOT and vowel space }\end{array}$ & $\begin{array}{l}9 \text { children with CAS who produced } \\
\text { pseudowords in masked and } \\
\text { unmasked conditions had } 1.5 \text { times } \\
\text { higher rates of the masking effect } \\
\text { compared to controls with SD and } \\
\text { typical speech. }\end{array}$ & $\begin{array}{l}\text { luzzini-Seigel et al. } \\
\qquad(2015)\end{array}$ \\
\hline
\end{tabular}

Note. Studies focusing on feedforward/feedback processes are included in both sections, depending on the focus of the study. VOT = voice onset time; SD = speech delay. 
Table 2. Descriptive information for four research groups totaling 310 participants, including cohorts with idiopathic and neurogenetic CAS, Apraxia of Speech and Primary Progressive Apraxia of Speech, and Speech Delay.

\begin{tabular}{|c|c|c|c|c|c|c|c|c|c|c|c|}
\hline No. & Title & Cohort & Abbreviation & $n$ & \multicolumn{3}{|c|}{ Age (years) } & $\%$ Males & \multicolumn{3}{|c|}{ PCC } \\
\hline 1 & & Neurogenetic CAS & $\begin{array}{l}\text { CASN } \\
\text { Total }\end{array}$ & $\begin{array}{l}15 \\
37\end{array}$ & $\begin{array}{r}10.9 \\
9.8\end{array}$ & $\begin{array}{l}3.9 \\
4.7\end{array}$ & $\begin{array}{l}5-19 \\
4-23\end{array}$ & $\begin{array}{l}46.7 \\
56.8\end{array}$ & $\begin{array}{l}76.4 \\
72.5\end{array}$ & $\begin{array}{l}10.3 \\
11.8\end{array}$ & $\begin{array}{l}53.6-92.2 \\
36.8-94.3\end{array}$ \\
\hline \multirow[t]{3}{*}{3} & Adult-onset apraxia & Apraxia of speech & AOS & 10 & 63.3 & 12.9 & 45-82 & 70.0 & 89.3 & 7.7 & $68.9-95.1$ \\
\hline & & $\begin{array}{l}\text { Primary progressive } \\
\text { AOS }\end{array}$ & PPAOS & 12 & 70.7 & 10.1 & $53-84$ & 50.0 & 91.9 & 6.8 & $74.0-97.6$ \\
\hline & & & Total & 22 & 67.3 & 11.8 & $45-84$ & 59.1 & 90.7 & 7.1 & 68.9-97.6 \\
\hline 4 & Speech delay (SD) & Random cohort & SD1 & 82 & 4.4 & 1.3 & $3-9$ & 74.4 & 73.4 & 12.6 & $17.5-99.1$ \\
\hline
\end{tabular}

Note. PCC = percentage of consonants correct.

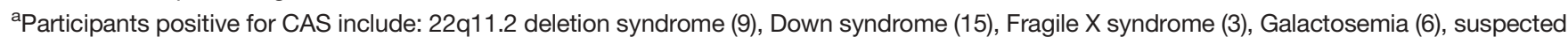
motor speech disorder (16), and traumatic brain injury (2).

4 to 23 years of age with idiopathic or neurogenetic CAS; 46 participants, 3 to 18 years of age with the complex neurodevelopmental disorders (CND) listed in the Table 2 footnote; 22 participants, 45 to 84 years of age with two types of AAS: AOS or primary progressive apraxia of speech (PPAOS); and 205 participants, 3 to 9 years of age assembled from four databases of children with SD. Participants within each of the four groups were subsets of those in Groups 1, 2, 3, and 5 in the second article in this series (PM II; Shriberg et al., 2017b) whose files included data on the measure used in the current study. Their sex distributions and their average speech status as quantified by the percentage of consonants correct were essentially the same as reported in PM II and consistent with the literatures in CAS, AAS, and SD. All participants were consented or assented using forms approved by their local and University of Wisconsin-Madison internal review boards. Data from participants with CND (Group 2) are only used for one of the later analyses to be described.

\section{Measures}

Data for the following analyses were obtained from conversational speech samples and from the syllable repetition task (SRT; Shriberg et al., 2009). Procedures to obtain, reduce, and analyze the speech, prosody, and voice data from the conversational speech samples were described or referenced in PM I, including reliability estimates for all perceptual and acoustic data reduction tasks. As described in PM I, all speech, prosody, and voice signs were obtained from the conversational speech samples standardized using chronological age and sex data from the reference databases of typical speakers. SRT scores for participants in the CAS groups were standardized using participants' sex and nonverbal age. SRT scores for participants in the AAS and SD groups were standardized using participants' sex and chronological age with the assumption that participants in these groups were within the normal range of intelligence. Scores on another index described later in this article, the PrecisionStability Index (PSI; Shriberg et al., 2010a), were also standardized using participants' chronological age and sex. It is useful to review briefly the three principle sources for the findings to be described in Results.

\section{The SRT}

The primary SRT score is a percentage correct imitation score termed the SRT Performance scale. Each of 50 consonant targets in the SRT's 18 nonsense words is scored as correctly or incorrectly repeated, yielding a Performance score conventionally interpreted as a measure of phonological memory. A percentage score for the Memory subscale of the SRT uses a ratio of the percentage of correctly repeated three-syllable nonsense words to the correctly repeated two-syllable nonsense words to quantify the effect of increased memory load on respondents' correct repetitions of nonsense words. Percentage scores for two other measures derived from speakers' responses to the SRT stimuli_Encoding and Transcoding - are interpreted as indicating the outcomes of these processes, each with implications for acquiring, storing, and retrieving phonological representations of real words. Encoding is the percentage of within-class substitution errors on the SRT, which is interpreted as successful encoding of at least the 
feature of the target compared to out-of-feature class substitution errors. Transcoding is the percentage of repetitions of SRT items that include additions, typically of homorganic or heterorganic nasals (Shriberg et al., 2009). Because such additions in participants with CAS were observed on nonsense words as short as two syllables (e.g., "banda" for "bada"), they were interpreted as more likely due to a representational deficit in encoding and/or memory/ retrieval, than to a transcoding deficit in motor planning or motor programming. As with most measures in this article series, transcoding scores are directionally adjusted so that lower raw score percentages, and lower corresponding $z$-scores indicate lower transcoding performance.

\section{The Prosody-Voice Screening Profile}

The Prosody-Voice Screening Profile (PVSP; Shriberg, Kwiatkowski, \& Rasmussen, 1990) yields percentage scores in three prosodic (Phrasing, Rate, Stress) and four voice (Loudness, Pitch, Laryngeal Quality, and Resonance) domains, based on the occurrence of inappropriate codes from optimally 24 utterances in a continuous speech sample determined to be eligible for coding. Inappropriate prosody and voice characteristics are perceptually coded using a set of 32 PVSP codes (Shriberg et al., 1990), with PVSP percentage scores expressing the percentage of utterances that were judged as appropriate for each of the seven prosody and voice domains. In the analysis to follow, the focus is on standardized findings for the two prosodic domains of Stress and Rate. As will be described, information from some of the perceptually based PVSP codes (e.g., Slow Speaking Rate) was also obtained from the acoustic procedures used in the PM, yielding two estimates of participant competence for some prosodic signs.

\section{The PM}

Last, it is useful to preface findings with a brief review of relevant PM terms and concepts as described in PM I, PM II, and the PM Technical Report (Tilkens et al., 2017). An inappropriate pause is defined as a between-words pause that occurs either at an inappropriate linguistic place in continuous speech and/or has one or more inappropriate articulatory, prosodic, or vocalic features within the pause or in a sound segment preceding or following the pause. The PM score is the total of four types of inappropriate pauses (termed Type I pauses) in a continuous speech sample divided by one less than the total number of words, with the quotient subtracted from 100 so that lower percentage scores indicate higher occurrences of inappropriate pauses. Abrupt inappropriate pauses are characterized acoustically by an immediate amplitude rise or fall time, respectively, on the onsets or offsets of phonemes following or preceding inappropriate pauses. The abrupt onset or offset is audible and typically visually perceptible on a spectrographic display. Change pauses have notable changes in loudness, pitch, or rate relative to phonemes, syllables, or words preceding or following the inappropriate pause. Grope pauses occur during the inappropriate pause and therefore can be identified only by acoustic information consistent with articulatory movement. The fourth Type I inappropriate pause, alone, is not associated with any preceding, concurrent, or following segmental or suprasegmental event - it is solely a pause that is inappropriate for the grammatical context. As described in the PM Technical Report, abrupt inappropriate pauses comprised $49.7 \%$ to $72.8 \%$ of the four types of inappropriate between-words pauses (Type I) used to calculate the PM scores of participants in the three participant groups $(\mathrm{CAS}=65.6 \%, \mathrm{CND}=72.8 \%$, and AAS $=49.7 \%$ ). Within the abrupt inappropriate pauses that occurred for the three participant groups, $99.4 \%$ to $100 \%$ occurred on postpausal phoneme onsets.

\section{Results and Discussion \\ Representational Deficits in CAS}

\section{Encoding and Memory Processes}

Table 3 includes findings for variables obtained from the SRT. The upper section of Table 3 includes descriptive statistics for the raw percentage scores, ratio scores (memory), and the $z$-scores for each of the four SRT variables for the participants with SD, CAS, and AAS described in Table 2. SRT scores were available only for those participants in each group who were assessed after this measure became available. As described previously, lower mean percentages on the Performance, Encoding, and Transcoding subscales, lower ratios on the Memory subscale, and lower $z$-scores on each of the four measures indicate lower competence. Notice the effect of the nonverbal age-sex $z$-scores standardization of the raw scores. Some relatively small between-groups differences in raw scores were associated with relatively large between-groups differences when transformed to $z$-scores that adjusted for possible between-groups cognitive differences.

The lower section of Table 3 includes inferential statistics (Hedges-corrected effect size [Hedges \& Olkin, 1985]; effect size adjective; and confidence interval [CI]) for comparison of each of the three participant groups with one another. CIs not crossing zero are statistically significant. As shown in the footnote to Table 3, the effect size adjectives are Cohen's (1988) adjective classifications for mean between-groups differences termed Small (>0.2), Medium $(>0.5)$ and Large $(>0.8)$ standard deviation units, augmented with adjective classifications for effect sizes termed Very Large (>1.0) and Extremely Large (>2.0). The following sections describe four findings of interest in Table 3, including interpretation of each finding relative to the first part of the hypothesis posed in the statement of the problem - that representational constraints are core deficits in CAS.

First, the data in the first two rows of the upper section of Table 3, which compare the four SRT scores of participants with SD to those of age-sex-matched typical speakers, indicated that none of the four mean $z$-scores of participants with SD was below $1 S D$ unit from the scores of typical speakers (Performance $=-0.64$; Encoding $=-0.18$; Memory $=-0.42$, Transcoding $=-0.75)$. As described in the reference citation for the SRT, the consensus in the 
Table 3. Syllable repetition task (SRT) findings for participants in the childhood apraxia of speech (CAS), adult-onset apraxia of speech (AAS), and speech delay (SD) groups.

\begin{tabular}{|c|c|c|c|c|c|c|c|c|c|c|c|c|}
\hline \multirow[b]{2}{*}{ Group } & \multicolumn{12}{|c|}{ Descriptive statistics } \\
\hline & $n$ & $M$ & $S D$ & $n$ & $M$ & $S D$ & $n$ & $M$ & $S D$ & $n$ & $M$ & $S D$ \\
\hline SD & 119 & & & 121 & & & 119 & & & 119 & & \\
\hline Percentage & & 67.8 & 16.4 & & 50.8 & 19.8 & & 0.77 & 0.20 & & 82.4 & 15.8 \\
\hline z-score & & -0.64 & 1.04 & & -0.18 & 1.01 & & -0.42 & 1.22 & & -0.75 & 1.56 \\
\hline$z$-score & & -1.80 & 1.73 & & -0.71 & 0.69 & & -1.13 & 1.38 & & -2.45 & 2.02 \\
\hline AAS $(\mathrm{PM}+)$ & 16 & & & 14 & & & 16 & & & 16 & & \\
\hline Percentage & & 77.4 & 15.6 & & 44.5 & 21.8 & & 0.85 & 0.15 & & 75.7 & 21.9 \\
\hline$z$-score & & -2.37 & 2.27 & & -0.73 & 0.97 & & -1.64 & 2.49 & & -3.46 & 2.20 \\
\hline \multicolumn{13}{|c|}{ Inferential statistics using z-scores } \\
\hline \multirow[t]{2}{*}{ Comparison } & \multicolumn{3}{|c|}{ Performance } & \multicolumn{3}{|c|}{ Encoding } & \multicolumn{3}{|c|}{ Memory } & \multicolumn{3}{|c|}{ Transcoding } \\
\hline & effect size ${ }^{a}$ & & & effect size & & & effect size & & & effect size & & \\
\hline
\end{tabular}

Note. $\mathrm{PM}+=$ positive for pause marker; $\mathrm{Cl}=$ confidence interval.

${ }^{a}$ Effect size: Small $(S)>0.2$; Medium $(M)>0.5$; Large $(L)>0.8$; Very Large $(M)>1.0$; Extremely Large $(E)>2.0$. Significant effect sizes are underlined.

speech sound disorder (SSD) literature is that nonword imitation tasks are sensitive to the language component of speech-language delay, but are only low to moderately associated with SD (Shriberg et al., 2009). Consistent with the wide age range of participants in this group shown in Table 2 (3-9 years), only some had language impairment at the time they were administered the SRT, with individual differences likely in the type and severity of language impairment in participants who had comorbid speechlanguage impairment. In a population sample of monolingual English-speaking 6-year-old children, approximately $11 \%-15 \%$ of children with persisting SD had specific language impairment (Shriberg, Tomblin, \& McSweeny, 1999). Thus, the present nonsignificant but lower averaged $z$-scores across the four SRT parameters in this fairly large sample of speakers with SD $(n=119)$ are interpreted as support for the construct validity of the SRT variables, particularly Transcoding (mean $z$-score $=-0.75$ ) as sensitive to some type of speech processing deficit. As described previously, both Encoding and Transcoding scores are posited to quantify deficits in auditory encoding and possibly somatosensory processes affecting the accuracy of underlying feature/phoneme/syllable/word and lexical stress representations. Performance and Memory scores are posited to quantify storage and retrieval processes in underlying representations (Shriberg et al., 2012).

A second set of findings in Table 3 is the CAS participant data on the Performance, Memory, and Transcoding subscales of the SRT compared to findings for the participants with SD. As shown in the lower section of Table 3, participants in the CAS group had significantly lower $z$-scores than participants in the SD group on these three subscales of the SRT. The significant effect sizes ranged from -0.56 (Medium) to -1.01 (Very Large).
These findings are interpreted as support for the hypothesized representational deficits in CAS. To be specific, in comparison to children with $\mathrm{SD}$, the children, youth, and adults in the CAS group performed more poorly in the acquisition, storage, and/or retrieval of linguistic representations, as posited to be identified by the standardized Performance, Memory, and Transcoding scores on the SRT.

Third, only one of the two participant groups with apraxia of speech - the CAS group - had significantly lower standardized mean Encoding scores relative to participants with SD (effect size $=-0.56$; Medium; $\mathrm{CI}=-0.94,-0.17$ ). That is, as with participants with CAS as described above, participants with AAS had significantly lower $z$-scores on the Performance, Memory, and Transcoding subscales of the SRT; however, participants in the AAS group did not have significantly lower Encoding $z$-scores than participants with SD. This finding is consistent with the previous discussion of the consequences of congenital or early CAS for encoding deficits in representational processes compared to consequences for older participants with AAS.

The fourth set of findings of interest is the data in the last row of the bottom section of Table 3. There were no significant differences in the average standardized scores of participants with CAS compared to participants with AAS on each of the four metrics proposed to index representational processes. Thus, relative to their age-matched reference data, neither the group of participants with CAS nor the group with AAS averaged significantly more severe expression of the disorder than the other at the time of assessment. As shown in the last row of the lower section of Table 3, the nonsignificant effect sizes for the four betweengroups comparisons of CAS $z$-scores to AAS $z$-scores ranged from -0.03 to 0.48 . 
Taken together, the four sets of findings just discussed are consistent with the hypothesis that speakers with CAS experience deficits in both auditory-perceptual and memory elements of representational processes. Moreover, as reported in PM II and Table 2 of the present article, these findings meet the four criteria proposed previously for core CAS deficits: Data were obtained from participants with CAS in many etiological contexts, at early and late stages of expression of CAS, at many levels of severity of expression, and likely are not moderated or mediated by individual differences in intelligence, language, or other speech processing variables. As described previously, the finding that participants with AAS also had significantly lower $z$-scores than participants with SD on the Performance, Memory, and Transcoding subscales of the SRT, but not on the Encoding subscale, is consistent with the hypothesis that representational deficits are present in both CAS and AAS, but are limited to deficits in the storage and retrieval of representations in AAS. Substantive and statistical constraints could also account for the nonsignificant Encoding finding, however, including the possibilities that the SRT stimuli are less sensitive to differences in encoding processes in adults compared to other nonsense tasks, as well as possible power constraints associated with smaller cell sizes in the AAS compared to CAS groups.

\section{Feedforward and Feedback Processes}

As indicated in the statement of purpose, the behavioral measures and descriptive design of the present study do not provide information sufficient for testing hypotheses about possible feedforward (e.g., Niziolek, Nagarajan, \& Houde, 2013) or feedback (e.g., Tschida \& Mooney, 2012) deficits in CAS. Behavioral information presumed to indicate feedforward and feedback processes (e.g., Liss, 1998), however, can inform the present hypothesis of representational deficits in CAS.

Table 4 includes findings for two types of Type I inappropriate pauses signs presumed to require intact feedforward and feedback processes that provide information on representational processes. As described previously, grope occurs during an inappropriate pause and repetitions and revisions quantify repetitions/revisions of sounds, syllables, or words before or after an inappropriate pause. The third sign in Table 4, which also quantifies repetitions/revisions, is obtained from the PVSP described previously. The repetitions and revisions coded in the PVSP are defined similarly to those occurring in the PM, but are obtained from any of the 24 PVSP coded utterances by the transcriber, rather than the acoustics analyst who accomplishes the acoustic-aided PM scoring procedures. Thus, the two percentages posited to index the occurrence of representational deficits were obtained by different persons using different numerators and denominators. As represented in Figure 1, each of the speech signs assumes that the speaker is attempting to correct the product of an error signal, possibly from feedforward information in the case of groping and from feedback information for the two repetition/revision variables. The occurrence of each event is posited to require sufficiently intact representations against which to compare the products of all postrepresentational processes, including planning, programming, and execution. Two findings in Table 4 are of interest for the question posed.

First, as with the data for the SD group in Table 3, findings for SD participants in Table 4 indicate that they had very low occurrences of each of the three signs, with nonsignificant mean $z$-scores relative to typical speakers of $0.13,-0.15$, and 0.18 . Findings are interpreted to support the perspective that children with even moderate to severe SD do not differ from typically speaking children of the same chronological age and sex on the frequency of occurrence of these self-repair attempts. To be specific, the interpretation is that by definition, the phonological errors of children with SD are due to imprecise underlying representations, and so there are few attempts to self-correct. An alternative explanation for the lack of groping and selfcorrections in participants with SD is that they have deficits in both feedforward (i.e., grope) and feedback (i.e., repetition/ revision) processes. Although feedback deficits have a long history of research in children with speech errors (see Figure 1), feedforward deficits have not been well studied in SD. As noted next, emerging studies using different measurement modalities and research designs posit feedforward deficits in CAS (e.g., Iuzzini-Seigel, Hogan, Guarino, \& Green, 2015; Terband, Maassen, Guenther, \& Brumberg 2014). For the descriptive-behavioral methods of the present study, it seems parsimonious to attribute the lack of groping and self-repairs in participants with SD to deficits in the specification of underlying phonological representations required to motivate such behaviors.

The second finding in Table 4 is that, compared to their age-sex matched typically speaking peers, participants with CAS and participants with AAS had significantly more frequent occurrences of each of the three signs than participants with SD compared to their age-sex matched typically speaking peers. Effect sizes for the six between-groups comparisons shown in the lower section of Table 4 range from -0.54 (Medium) to -3.18 (Extremely Large). Findings for frequent repetitions/revisions in AOS are also interpreted as support for intact feedback processes that monitor the output from all pre-execution stages. The interpretation of findings indicating increased groping in both CAS and particularly in AAS is less clear. If participants with CAS have representational deficits in the specification of phonological representations, as claimed previously, they would not be motivated to grope for the correct articulatory postures to self-correct. As discussed in the next section, however, groping and self-corrections could be in response to transcoding deficits in addition to representational deficits, the hypotheses presently under inspection.

The third finding, as shown in the lowest row of the bottom section of Table 4, is that on two of the three signs indicating attempts to self-correct, the AAS group's standardized scores were significantly lower than those of the participants with CAS. Findings are interpreted as support for differences in the type of representational deficits in CAS 
Table 4. Pause marker (PM) and Prosody-Voice Screening Profile (PVSP) findings for participants in the childhood apraxia of speech (CAS), adult-onset apraxia of speech (AAS), and speech delay (SD) groups.

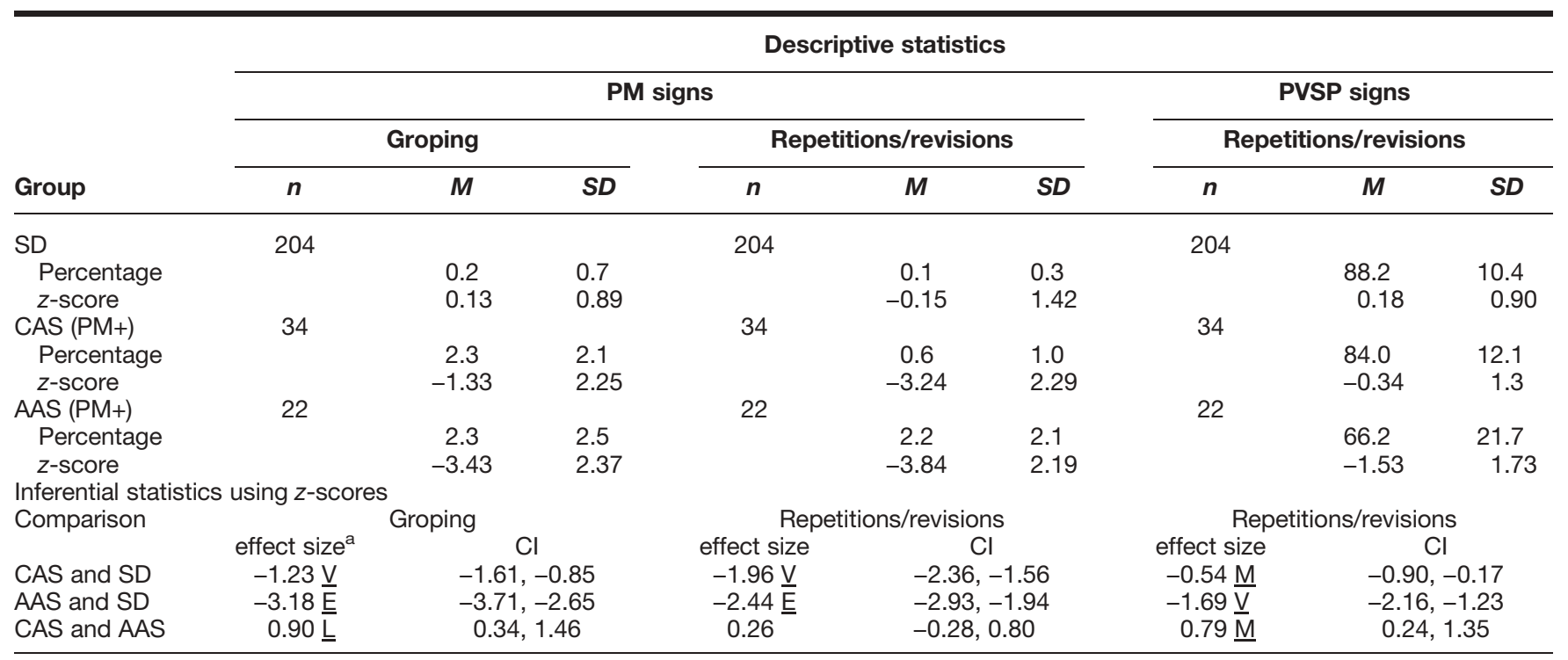

Note. See text for the PVSP category of repetitions/revisions under Phrasing. $\mathrm{Cl}=$ confidence interval; PM+ = positive for pause marker. ${ }^{a}$ Effect size: Small $(S)>0.2$; Medium $(M)>0.5$; Large $(L)>0.8$; Very Large $(V)>1.0$; Extremely Large $(E)>2.0$. Significant effect sizes are underlined.

compared to AAS. To be specific, whereas participants with CAS have deficits in both the auditory-perceptual encoding and memory constraints associated with representational deficits, the representational deficits of participants with AAS may be primarily in timely access to and retrieval of stored representations. That is, the increased rates of occurrence for two of the three signs in Table 4 for participants with AAS compared to rates in CAS support intact representations and intact feedforward (groping) and feedback (repetitions/revisions) processes in AAS, with the searching and self-correcting behaviors motivated by intact monitoring of transcoding deficits.

\section{Transcoding Processes in CAS}

As described in PM I, we have proposed transcoding as a cover term for speech planning and programming processes, primarily to accommodate the lack of consensus on the processing domains of each term within and among basic and applied disciplines in speech motor control. In the CAS literature, the terms planning and programming are often used interchangeably or more frequently, left undifferentiated using the theoretically noncommittal slash convention. We follow van der Merwe's $(1997,2009)$ influential proposal in which planning is posited to denote motor goals and the articulatory structures required to achieve them, whereas programming denotes muscle-specific goals including muscle tone, movement velocity, force, and range. Because the present descriptive linguistic methods are not instrumented to discriminate such differences at neuromuscular levels of observation, findings cannot be marshalled in support of just one or both speech processing deficits in
CAS. Therefore, transcoding replaces planning/programming in most places in the following discussion, retaining the same lack of specificity about alternative stages and goals.

\section{Segmental Findings}

Table 5 includes findings for four measures of the precision and stability of participants' articulation during continuous speech that are presumed to quantify transcoding deficits. The first variable in Table 5, termed the PSI, includes 32 signs of precision and stability assessed using a system of narrow phonetic diacritics (Shriberg \& Kent, 2013) and procedures for acoustic analyses (Shriberg et al., 2010a, 2010b). As described briefly in PM I and in more detail elsewhere (Mabie \& Shriberg, 2017), the PSI was developed as a measure to identify and quantify the MSD in Figure 1 termed MSD-Not Otherwise Specified. The other three variables in Table 5 are subscales from a measure termed the Diacritic Modification Index (DMI; Shriberg, Allen, McSweeny, \& Wilson, 2001). The DMI aggregates and calculates the percentage of each diacritic that occurs in a speech sample - in the present case, in a continuous speech sample. DMI subscales are available for each of six phonetic-level modifications of sounds, including changes in place, manner, voicing, duration, force, and additions (i.e., onglides and offglides; see Appendix of Shriberg, 1993). Preliminary studies of DMI findings in children suspected positive for CAS indicated that the most frequent types of segmental distortions were transcribed as modifications of articulatory space (place), time (duration), and additions (Duffy [2007, 2013] terms the latter modifications complications). Diacritic characterization of imprecise articulation on the DMI includes both common 
Table 5. Precision-Stability Index (PSI) and Diacritic Modification Index (DMI) findings for participants in the childhood apraxia of speech (CAS), adult-onset apraxia of speech (AAS), and speech delay (SD) groups.

\begin{tabular}{|c|c|c|c|c|c|c|c|c|c|c|c|c|}
\hline \multirow[b]{3}{*}{ Group } & \multirow{2}{*}{\multicolumn{3}{|c|}{ PSI }} & \multicolumn{9}{|c|}{ DMI } \\
\hline & & & & \multicolumn{3}{|c|}{ Place changes (\%) } & \multicolumn{3}{|c|}{ Duration changes (\%) } & \multicolumn{3}{|c|}{ Additions (\%) } \\
\hline & $n$ & $M$ & $S D$ & $n$ & $M$ & $S D$ & $n$ & $M$ & $S D$ & $n$ & $M$ & $S D$ \\
\hline SD & 204 & & & 204 & & & 204 & & & 204 & & \\
\hline CAS (PM+) & 37 & & & 37 & & & 37 & & & 37 & & \\
\hline Percentage & & 57.1 & 10.3 & & 8.8 & 3.7 & & 2.6 & 1.6 & & 2.6 & 1.8 \\
\hline z-score & & -1.12 & 0.51 & & 2.99 & 1.70 & & 2.73 & 1.61 & & 3.30 & 1.89 \\
\hline AAS $(\mathrm{PM}+)$ & 22 & & & 22 & & & 22 & & & 22 & & \\
\hline Percentage & & 52.3 & 6.7 & & 3.2 & 1.5 & & 2.0 & 1.5 & & 3.6 & 2.2 \\
\hline z-score & & -1.43 & 0.37 & & 4.97 & 0.13 & & 3.42 & 1.68 & & 5.00 & 0.00 \\
\hline \multicolumn{13}{|c|}{ Inferential statistics using z-score } \\
\hline
\end{tabular}

Note. $\mathrm{PM}+=$ positive for pause marker; $\mathrm{Cl}=$ confidence interval.

${ }^{a}$ Effect size: Small $(S)>0.2$; Medium $(M)>0.5$; Large $(L)>0.8$; Very Large $(M)>1.0$; Extremely Large $(E)>2.0$. Significant effect sizes are underlined.

and uncommon clinical errors (e.g., distortions and distorted substitutions) and common and uncommon clinical distortions in the child phonology literature (see Appendix of Shriberg, 1993). Three findings in Table 5 support the hypothesis that these articulatory modifications occur at transcoding stages of speech processing, and likely include deficits in both planning and programming.

First, as indicated in the first two rows in the top section of Table 5, participants with SD were not significantly less precise on the four articulatory variables than typical speakers of the same age and sex. Their mean PSI score of $81.7 \%(Z=-0.07)$ was not significantly lower than the PSI of typical speakers, and their percentages of diacritic modifications in place $(5.1 \% ; Z=0.37)$, duration $(1.3 \%$; $Z=0.80)$, and additions $(1.3 \% ; Z=1.01)$ were more than $1 S D$ unit higher than typical speakers only for additions. As described in Table 2, the participants with SD in the present study include a wide range of ages and severity, with all participants meeting the SD criteria of having deletion and substitution errors inappropriate for their age at the time of assessment. These findings are interpreted to be consistent with findings in the child phonology literature that children with even severe SD do not have high frequencies of place and duration modifications of phonemes, generally viewed, respectively, as signs of spatial and temporal imprecision.

Second, relative to participants with both typical speech and SD, participants with CAS and AAS had significantly reduced precision and stability as assessed with the four measures in Table 5. The mean PSI scores of participants with CAS and AAS, respectively, were $57.1 \%$ and $52.3 \%$, compared to PSI mean for the 204 participants with SD of $81.7(S D=9.9)$. $Z$-score effect size comparisons with $\mathrm{SD}$ scores for CAS and AAS, respectively, were -2.50 and -3.41 (both classified as Extremely Large). These findings are interpreted as support for the hypothesis that speakers with CAS and speakers with AAS have transcoding (i.e., planning/programming) deficits.

Third, the between-groups CAS-AAS effect size comparisons for three of the four articulatory precision measures in Table 5 indicate that the participants with AAS had significantly lower speech precision relative to their typically speaking peers than the participants with CAS relative to their typically speaking peers. As shown in the bottom section of Table 5, significant effect sizes for the PSI total (0.66; Medium), place changes ( -1.44 ; Very Large), and additions ( -1.12 ; Very Large) indicated greater association of apraxia of speech with speech precision in participants with AAS than in participants with CAS. This standardized comparison appears to be the first finding supporting increased transcoding deficits in AAS compared to CAS, but as discussed in PM I, the inclusionary criteria for the present study (i.e., ability to complete a 2-hr protocol) may have truncated the lower range of severity in CAS participants. As will be shown in PM IV, approximately $50 \%$ of participants with CAS in the present data set, including participants with CND, were classified as Mild CAS using the four-category PMI.

\section{Suprasegmental Findings}

Table 6 is a summary of the rate and stress findings for participants in the three groups. The two measures of rate were computed from acoustic measurements of utterance durations in continuous speech samples. Speaking rate 
Table 6. Standardized conversational speech findings for speaking rate, articulation rate, and sentential stress for participants in the childhood apraxia of speech (CAS), adult-onset apraxia of speech (AAS), and speech delay (SD) groups.

\begin{tabular}{|c|c|c|c|c|c|c|}
\hline Group & \multicolumn{2}{|c|}{ Speaking rate (syllable/s) } & \multicolumn{2}{|c|}{ Articulation rate (syllable/s) } & \multicolumn{2}{|c|}{$\begin{array}{c}\text { Sentential stress } \\
\text { (\% appropriate utterances) }\end{array}$} \\
\hline \multicolumn{7}{|l|}{$\operatorname{SD}(n=204)$} \\
\hline Raw score (ms) & 3.2 & 0.6 & 3.5 & 0.6 & 88.9 & 9.6 \\
\hline Raw score (ms) & 2.7 & 0.6 & 3.2 & 0.6 & 60.1 & 22.7 \\
\hline \multicolumn{7}{|l|}{ AAS (PM+) $(n=22)$} \\
\hline Raw score (ms) & 2.1 & 0.5 & 2.7 & 0.6 & 50.4 & 26.3 \\
\hline$z$-score & -3.26 & 1.33 & -3.01 & 1.50 & -4.09 & 1.62 \\
\hline \multicolumn{7}{|c|}{ Inferential statistics using $z$-scores } \\
\hline Comparison & \multicolumn{2}{|c|}{ Speaking rate (syllable/s) } & \multicolumn{2}{|c|}{ Articulation rate (syllable/s) } & \multicolumn{2}{|c|}{$\begin{array}{l}\text { Sentential stress (\% appropriate utterances) } \\
\text { effect size }\end{array}$} \\
\hline
\end{tabular}

Note. $\mathrm{PM}+=$ positive for pause marker; $\mathrm{Cl}=$ confidence interval.

${ }^{a}$ Effect size: Small $(S)>0.2$; Medium $(M)>0.5$; Large $(L)>0.8$; Very Large $(M)>1.0$; Extremely Large $(E)>2.0$. Significant effect sizes are underlined.

includes both articulation time and pause time in syllables per second, whereas articulation rate subtracts pause time, computing syllables per second using only the remaining articulation time. Both the rate and stress signs of apraxia of speech (and other MSD) are included in Table 6 because each may inform questions of cognitive and articulatory contributions to rate and stress in apraxia of speech. Last, as shown in the top section of Table 6, raw and standardized scores were obtained for each participant's percentage of appropriate sentential stress. Appropriate sentential stress is the percentage of utterances coded as having appropriate stress in the PVSP analyses (i.e., the percentage of utterances that do not include at least one occurrence of excessive-equal or misplaced stress; Shriberg et al., 1990). Four findings in Table 6 are interpreted as support for transcoding deficits in AOS.

First, as shown in the first row in the top section of Table 6, participants with SD did not differ from their typically speaking peers in either of the two measures of rate or in sentential stress. $Z$-scores for the three variables ranged from -0.14 to 0.16 . The present findings support use of rate and stress measures as endophenotypes to differentiate speakers with the class of SSD termed MSD (see Figure 1) from speakers with either of the other two classes of SSD (SD or speech errors [SE]). That is, slow rate and inappropriate stress do not differentiate the several types of dysarthria from one another or from apraxia within the class of MSD (Duffy, 2013), because both signs can reflect deficits at representational, transcoding, and/or execution stages of speech production.

Second, as shown by the means data for the raw scores and $z$-scores of speakers with CAS and AAS in the top section of Table 6, both groups had slower speaking rates, slower articulation rates, and more utterances with inappropriate sentential stress compared to the $z$-scores obtained on these variables for participants with SD. All six effect sizes for these comparisons in the lower section of Table 6 were significant, with Very Large or Extremely Large effect sizes ranging from -1.41 to -3.42 . These findings are proposed to support transcoding deficits in both CAS and AAS.

A third set of findings in Table 6 supports previous discussion of the hypothesis of increased memory deficits in AAS compared to CAS. The raw scores and standardized differences in speaking rate and articulation rate between participants with CAS compared to those with AAS indicated that participants with AAS were both absolutely and relatively (compared to their age-sex peers) slower talkers than participants with CAS. Effect sizes for the age-sex standardized speaking rate and articulation rate comparisons, respectively, were 1.49 (Very Large) and 1.25 (Very Large). The inference in both comparisons is that the slower rates were at least in part due to slower access times to both linguistic and motor representations, particularly for the speaking time comparisons that included pause times. In addition to this third finding, participants with AAS also had a lower percentage of utterances with appropriate stress ( $M=50.4 \%$ of utterances) compared to participants with CAS $(M=60.1 \%)$, with a Moderate effect size (0.54).

\section{Summary}

As described in the statement of the problem, the first part of the question posed in this article addressed the strength of support for including core deficits in both representational and transcoding processes in the phenotype of CAS. We have interpreted findings in Tables 3 and 4 as support for core representational deficits in CAS and 
findings in Tables 5 and 6 as support for core transcoding deficits in CAS. Findings in these tables were also interpreted as support for a corollary hypothesis that compared to participants with CAS, participants with AAS do not have deficits in the accuracy of their phonological representations. Support for the latter hypothesis was based primarily on the increased occurrences of groping and repetitions/ revisions in participants with AAS, compared to the significantly lower occurrence rates of these behaviors in participants with CAS. Such attempts to achieve or correct articulatory and prosodic behaviors were posited to result from feedforward and feedback processes that detect errors in transcoding appropriately specified linguistic representations to pre-articulatory commands. Therefore, the representational deficits of participants with AAS were posited to be memory constraints limiting timely access to and retrieval of phonological representations.

\section{Appropriate and Inappropriate Between-Words Pauses Findings}

The second part of the question in the statement of purpose is the theoretical coherence of the PM measure with posited CAS deficits in representational and transcoding processes. In addition to its primary task of identifying speakers who are true positives for CAS, are the pause and speech elements of the PM coherent, respectively, with representational and transcoding deficits?

Figure 2 includes PM findings interpreted as support for the theoretical coherence of the PM with core deficits in CAS. Because preliminary analyses indicated no significant differences or trends between findings for participants with idiopathic CAS and participants with CAS in the context of CND, it was statistically efficient to combine the two groups into one group titled CAS \& CND. The upper two panels in Figure 2 include group data on the percentage of appropriate between-words pauses (hereafter, appropriate pauses) for participants with SD, CAS \& CND, and AAS. The upper left panel includes descriptive findings $(M, S D)$ and inferential statistics (significant effect sizes; strength of effect sizes) for the raw percentages of appropriate pauses. Appropriate between-words pauses were pauses of at least $150 \mathrm{~ms}$ occurring in grammatically appropriate contexts, such as at phrase and utterance boundaries. The upper right panel includes these findings standardized for sex and nonverbal mental age ( $z$-scores) for the CAS \& CND participants and sex and chronological age for the AAS participants. The lower two panels in Figure 2 includes the same descriptive and inferential information for the three groups' percentages of abrupt inappropriate betweenwords pauses. As described previously, inappropriate abrupt between-words pauses of $150 \mathrm{~ms}$ or more (hereafter, abrupt pauses) are the most frequent of the four types of inappropriate pauses used to calculate the PM score. Pearson correlation coefficients between PM scores and the percentage of abrupt Type I pauses for the CAS, CND, and AAS groups, respectively, were $-0.957,-0.934$, and -0.700 .
The between-groups findings in Figure 2 for both the appropriate pauses and the abrupt inappropriate pauses are interpreted as support for the theoretical coherence of the PM with the speech processing deficits discussed in CAS findings reviewed in Tables 3 through 6 . First, findings in the upper panels in Figure 2 indicate that participants in the AAS group averaged significantly more frequent appropriate pauses $(M=18.0 \% ; S D=9.6 \%)$ than both speakers in the SD group $(M=11.9 \% ; S D=6.1 \%)$ and in the combined CAS \& CND group $(M=12.4 \% ; S D=7.0 \%)$. The average $z$-scores of AAS participants $(M=2.6 ; S D=1.9)$ were significantly higher (effect sizes greater than $1 S D$ unit) than their typically speaking age-sex-matched peers. In contrast, the mean $z$-scores for the percentages of appropriate pauses for participants in the SD group and participants in the CAS \& CND group were within $1 S D$ of the means of sex and nonverbal mental age-matched typical speakers and significantly lower than those of the participants in the AAS group. These findings for the higher standardized frequency of occurrence of appropriate pauses in AAS but not in CAS are interpreted as support for the claim that participants with AAS experience deficits in accessing representations and/or creating motor plans/programs beyond those typically associated with advancing age. Thus, attributes of the pause element of the PM are viewed as theoretically coherent with neurocognitive substrates of apraxia of speech.

Findings in the lower two panels of Figure 2 are also interpreted as support for the coherence of the PM with speech processing deficits in CAS. As shown in both the average raw percentages of occurrence of abrupt inappropriate pauses and the sex and nonverbal mental age matched $z$-scores, the two groups of participants with AOS (CAS \& CND and AAS) had essentially similar percentages of occurrences of abrupt pauses. That is, as well as documenting the high occurrence of abrupt pauses in the CAS \& CND and AAS groups in comparison to speakers with SD and typical speakers, respectively, these data document the similarity in what are interpreted as planning and programing deficits in speakers with apraxia of speech.

The claim of theoretical coherence is further based on the comparison of the findings in Figure 2 for the central PM sign - the pausal and speech elements of abrupt inappropriate between-words pauses - to other proposed markers of apraxia of speech in speakers of widely varying age, intellectual and language status, and neurological and neurodevelopmental backgrounds. To be specific, the pause element of abrupt pauses is posited to reflect slowed retrieval time in apraxia of speech and the abrupt speech onset element is posited to reflect the transcoding (i.e., both planning and programming) deficit. Thus, the claim of theoretical coherence for the PM is based on the finding that abrupt inappropriate pauses (the most frequently occurring type of inappropriate pauses) embody the two processing deficits posited for CAS - representational deficits and transcoding deficits. Moreover, if a central criterion for a core behavioral sign of CAS is that it is among the last to normalize or may never normalize (PM I), findings in 
Figure 2. Summary findings for the percentage of occurrence of appropriate and abrupt inappropriate pauses in participants in the speech delay (SD), combined childhood apraxia of speech (CAS) and complex neurodevelopmental disorders (CND), and adult-onset apraxia of speech (AAS) groups.

\section{Appropriate Pauses}
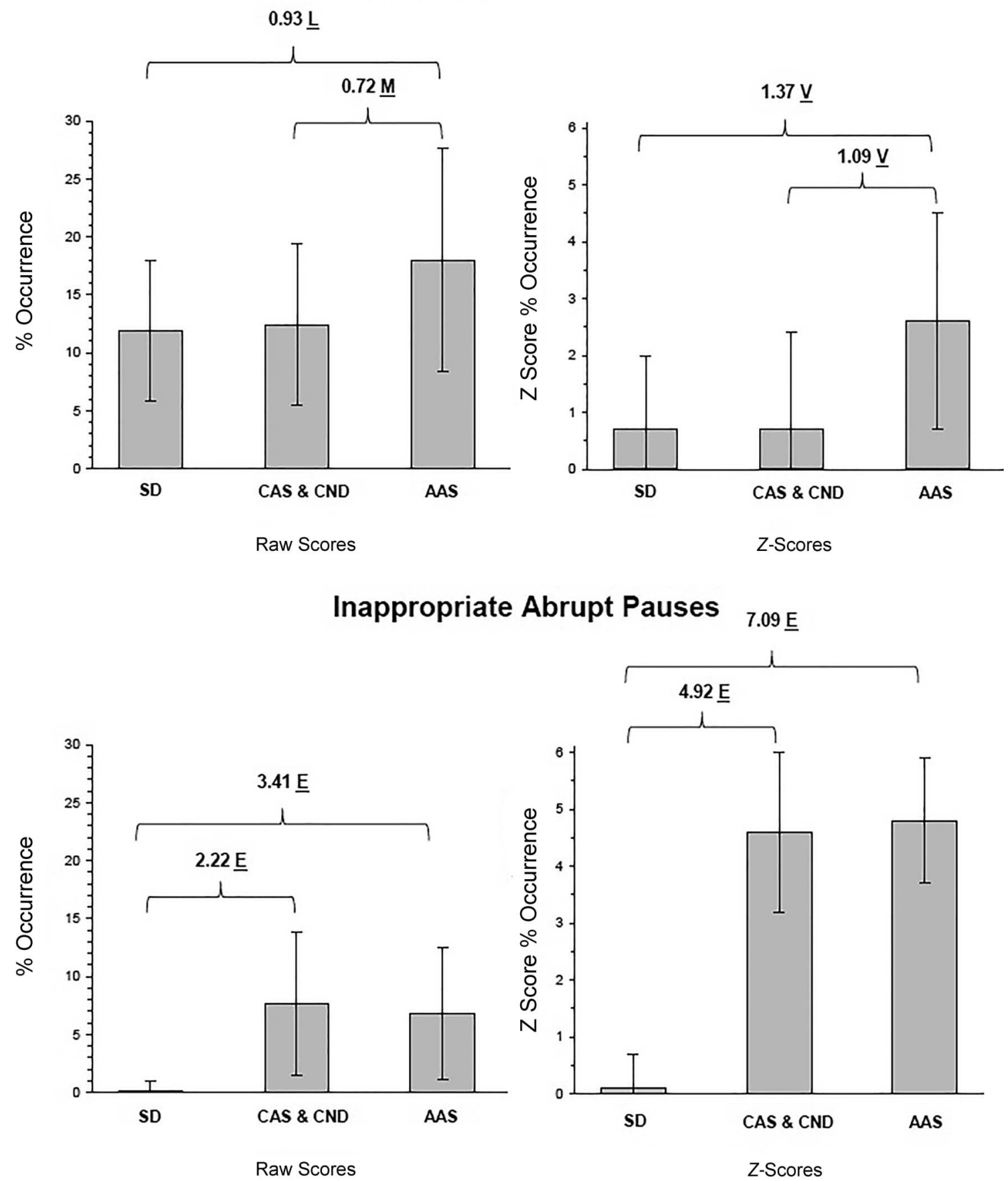

Effect size: Small $(S)>0.2$; Medium $(M)>0.5$; Large $(L)>0.8$; Very Large $(V)>1.0$; Extremely Large $(E)>2.0$. Significant effect sizes are underlined. 
Figure 2 for participants as old as 23 years in the CAS group (and older participants in the AAS group) are consistent with the perspective that abrupt inappropriate pauses are core signs of apraxia of speech. As discussed previously and later, the present study was not instrumented to explicate contributions of respiratory, laryngeal, and supralaryngeal mechanisms to what are termed abrupt pauses.

\section{Summary and Conclusions}

The present study has described two sets of findings interpreted as support for core representational deficits in CAS: (a) participants with CAS had significantly lower standardized scores than typical speakers and participants with SD of the same age and sex on the Performance, Encoding, Memory, and Transcoding (interpreted as assessing auditory-perceptual encoding) scales of the SRT (see Table 3); and (b) they had significantly higher percentages of attempts to correctly produce speech (groping) and selfcorrect speech errors (repetitions/revisions) in comparison to participants with $\mathrm{SD}$, but significantly lower percentages of these behaviors in comparison to participants with AAS (see Table 4). The latter finding for participants with CAS was attributed to their less well specified phonological representations.

In support of transcoding deficits in CAS, the present study found that participants with CAS had significantly reduced segmental precision and stability (see Table 5), slower speech rates, and more frequent inappropriate sentential stress compared to these behaviors in the continuous speech of typically speaking controls and participants with SD (see Table 6). They also had significantly higher standardized percentages of inappropriate between-words pauses, but (unlike findings for participants with AAS) typical standardized percentages of appropriate pauses (see Figure 2) in comparison to age-sex-matched peers. On the question of whether such behaviors meet criteria for core deficits, the segmental errors and inappropriate rate and stress findings in Tables 5 and 6 were present both in some of the youngest and some of the oldest participants with CAS. Anecdotal accounts of CAS also indicate that even for speakers who have normalized speech and prosody in natural discourse, attempts to imitate phonetically challenging words and nonsense words can evoke former signs of CAS (e.g., Hennessy \& Hennessy, 2013; Jakielski \& Green, 2008).

Findings from the present study were interpreted to support the theoretical coherence of the PM with representational and transcoding deficits in CAS. To be specific, the occurrence of between-words pauses is posited to index a deficit at any one or more stages of speech processing, and the four Type I inappropriate pauses are posited to have the potential to inform explanatory accounts of CAS at neurolinguistic levels. From a number of speech motor control, psychometric, and treatment perspectives and goals, research on abrupt inappropriate between-words pauses is viewed as having attractive potential for an eventual explanatory account of CAS.

\section{Acknowledgments}

This research was supported by National Institute on Deafness and Other Communication Disorders Grant DC000496 and by a core grant to the Waisman Center from the National Institute of Child Health and Development (Grant HD03352). Authors CT and HK made the original and substantial continuing contributions leading to the development of the PM. We are grateful to the following colleagues and collaborators for their significant contributions to this research: Len Abbeduto, Nancy Alarcon, Becky Baas, Adriane Baylis, Richard Boada, Roger Brown, Stephen Camarata, Thomas Campbell, Richard Folsom, Lisa Freebairn, Jordan Green, Barbara Lewis, Christopher Moore, Katherine Odell, Bruce Pennington, Nancy Potter, Jonathan Preston, Erin Redle, Heather Leavy Rusiewicz, Alison Scheer-Cohen, Kristie Spencer, Ruth Stoeckel, Bruce Tomblin, Jennifer Vannest, and Emily White. We also thank the many participants, parents of participants, and research colleagues who have contributed insights on needs and issues in diagnostic research in CAS.

\section{References}

Bishop, D. V. M. (1997). Cognitive neuropsychology and developmental disorders: Uncomfortable bedfellows. The Quarterly Journal of Experimental Psychology A, 50, 899-923.

Blech, A., Springer, L., \& Kröger, B. J. (2007). Perceptual and acoustic analysis of vowel productions in words and pseudo words in children with suspected childhood apraxia of speech. Proceedings of the 16th International Congress of Phonetic Sciences (pp. 2013-2016). Saabrücken, Germany: Universität des Saarlandes.

Chilosi, A. M., Lorenzini, I., Fiori, S., Graziosi, V., Rossi, G., Pasquariello, R., ... Cioni, G. (2015). Behavioral and neurobiological correlates of childhood apraxia of speech in Italian children. Brain and Language, 150, 177-185.

Cohen, J. (1988). Statistical power analysis for the behavioral sciences (2nd ed.). Mahweh, NJ: Erlbaum.

Duffy, J. R. (2007). Motor speech disorders: History, current practice, future trends and goals. In G. Weismer (Ed.) Motor speech disorders (pp. 7-56). San Diego, CA: Plural.

Duffy, J. R. (2013). Motor speech disorders: Substrates, differential diagnosis, and management (3rd ed.). St. Louis, MO: Mosby.

Froud, K., \& Khamis-Dakwar, R. (2012). Mismatch negativity responses in children with a diagnosis of childhood apraxia of speech (CAS). American Journal of Speech-Language Pathology, 21, 302-312.

Grigos, M. I., Moss, A., \& Lu, Y. (2015). Oral articulatory control in childhood apraxia of speech. Journal of Speech, Language, and Hearing Research, 58, 1103-1118.

Groenen, P., Maassen, B., Crul, T., \& Thoonen, G. (1996). The specific relation between perception and production errors for place of articulation in developmental apraxia of speech. Journal of Speech and Hearing Research, 39, 468-483.

Hedges, L., \& Olkin, I. (1985). Statistical methods for metaanalysis. Boston, MA: Academic Press.

Hennessy, K., \& Hennessy, K. (2013). Anything but silent: Our family's journey through childhood apraxia of speech. Tarentum, PA: Word Association.

Iuzzini-Seigel, J., Hogan, T., Guarino, A., \& Green, J. (2015). Reliance on auditory feedback in children with childhood apraxia of speech. Journal of Communication Disorders, 54, 32-42.

Jakielski, K., \& Green, M. (2008). Subclinical speech errors in adolescents with a history of speech impairment. Poster presented 
at the Annual Convention of the American Speech-LanguageHearing Association, Chicago, IL.

Kadis, D. S., Goshulak, D., Namasivayam, A., Pukonen, M., Kroll, R., De Nil, L. F., \& Lerch, J. P. (2013). Cortical thickness in children receiving intensive therapy for idiopathic apraxia of speech. Brain Topography, 27, 240-247.

Liss, J. M. (1998). Error-revision in the spontaneous speech of apraxic speakers. Brain and Language, 62, 342-360.

Maassen, B., Groenen, P., \& Crul, T. (2003). Auditory and phonetic perception of vowels in children with apraxic speech disorders. Clinical Linguistics and Phonetics, 17, 447-467.

Maassen, B., van der Meulen, S., \& Tissen, M. (1997). Acoustic evidence for deviant phonological encoding in children with Developmental Apraxia of Speech (DAS). Paper presented at the 18th Annual Symposium on Research in Child Language Disorders, Madison, WI.

Mabie, H. L., \& Shriberg, L. D. (2017). Speech and motor speech measures and reference data for the Speech Disorders Classification System (SDCS). (Technical Report No. 23). Retrieved from Phonology Project website: http://www.waisman.wisc.edu/ phonology/

Marion, M. J., Sussman, H. M., \& Marquardt, T. P. (1993). The perception and production of rhyme in normal and developmentally apraxic children. Journal of Communication Disorders, 26, 129-160.

Marquardt, T., Sussman, H. M., Snow, T., \& Jacks, A. (2002). The integrity of the syllable in developmental apraxia of speech. Journal of Communication Disorders, 35, 31-49.

McNeill, B. C., Gillon, G. T., \& Dodd, B. (2009). Phonological awareness and early reading development in childhood apraxia of speech (CAS). International Journal of Language \& Communication Disorders, 44, 175-192.

Mozzi, A., Forni, D., Clerici, M., Pozzoli, U., Mascheretti, S., Guerini, F. R., ... Sironi, M. (2016). The evolutionary history of genes involved in spoken and written language: Beyond FOXP2. Scientific Reports, 6:22157. https://doi.org/10.1038/ srep22157

Nijland, L., Maassen, B., van der Meulen, S., Gabreëls, F., Kraaimaat, F. W., \& Schreuder, R. (2002). Coarticulation patterns in children with developmental apraxia of speech. Clinical Linguistics and Phonetics, 16, 461-483.

Nijland, L., Terband, H., \& Maassen, B. (2015). Cognitive functions in childhood apraxia of speech. Journal of Speech, Language, and Hearing Research, 58, 550-565.

Niziolek, C., Nagarajan, S. S., \& Houde, J. F. (2013). What does motor efference copy represent? Evidence from speech production. The Journal of Neuroscience, 33, 16110-16116.

Preston, J. L., Molfese, P. J., Gumkowski, N., Sorcinelli, A., Harwood, V., Irwin, J. R., \& Landi, N. (2014). Neurophysiology of speech differences in childhood apraxia of speech. Developmental Neuropsychology, 39, 385-403.

Shriberg, L. D. (1993). Four new speech and prosody-voice measures for genetics research and other studies in developmental phonological disorders. Journal of Speech and Hearing Research, $36,105-140$.

Shriberg, L. D., Allen, C. T., McSweeny, J. L., \& Wilson, D. L. (2001). PEPPER: programs to examine phonetic and phonologic evaluation records [Computer software]. Madison, WI: Waisman Center Research Computing Facility, University of Wisconsin-Madison.

Shriberg, L. D., Aram, D. M., \& Kwiatkowski, J. (1997). Developmental apraxia of speech: III. A subtype marked by inappropriate stress. Journal of Speech, Language, and Hearing Research, 40, 313-337.
Shriberg, L. D., Fourakis, M., Hall, S., Karlsson, H. B., Lohmeier, H. L., McSweeny, J. L., ... Wilson, D. L. (2010a). Extensions to the Speech Disorders Classification System (SDCS). Clinical Linguistics \& Phonetics, 24, 795-824.

Shriberg, L. D., Fourakis, M., Hall, S., Karlsson, H. B., Lohmeier, H. L., McSweeny, J. L., .. Wilson, D. L. (2010b). Perceptual and acoustic reliability estimates for the Speech Disorders Classification System (SDCS). Clinical Linguistics \& Phonetics, 24, 825-846.

Shriberg, L. D., \& Kent, R. D. (2013). Clinical phonetics. (4th ed.). Boston, MA: Pearson Education.

Shriberg, L. D., Kwiatkowski, J., \& Rasmussen, C. (1990). The Prosody-Voice Screening Profile. Tucson, AZ: Communication Skill Builders.

Shriberg, L. D., Lohmeier, H. L., Campbell, T. F., Dollaghan, C. A., Green, J. R., \& Moore, C. A. (2009). A nonword repetition task for speakers with misarticulations: The syllable repetition task (SRT). Journal of Speech, Language, and Hearing Research, 52, 1189-1212.

Shriberg, L. D., Lohmeier, H. L., Strand, E. A., \& Jakielski, K. J. (2012). Encoding, memory, and transcoding deficits in childhood apraxia of speech. Clinical Linguistics \& Phonetics, 26, 445-482.

Shriberg, L. D., Strand, E. A., Fourakis, M., Jakielski, K. J., Hall, S. D., Karlsson, H. B., ... Wilson, D. L. (2017a). A diagnostic marker to discriminate childhood apraxia of speech from speech delay: I. Development and description of the pause marker. Journal of Speech, Language, and Hearing Research, 60, S1096-S1117. https://doi.org/10.1044/2016_ JSLHR-S-15-0296

Shriberg, L. D., Strand, E. A., Fourakis, M., Jakielski, K. J., Hall, S. D., Karlsson, H. B., ... Wilson, D. L. (2017b). A diagnostic marker to discriminate childhood apraxia of speech from speech delay: II. Validity studies of the pause marker (PM). Journal of Speech, Language, and Hearing Research, 60, S1118-S1134. https://doi.org/10.1044/2016_JSLHR-S-150297

Shriberg, L. D., Strand, E. A., Fourakis, M., Jakielski, K. J., Hall, S. D., Karlsson, H. B., ... Wilson, D. L. (2017c). A diagnostic marker to discriminate childhood apraxia of speech from speech delay: IV. The pause marker index. Journal of Speech, Language, and Hearing Research, 60, S1153-S1169. https://doi.org/10.1044/2016_JSLHR-S-160149

Shriberg, L. D., Strand, E. A., \& Mabie, H. L. (2017). Prevalence of speech and motor speech disorders in idiopathic speech delay and complex neurodevelopmental disorders. Manuscript submitted for publication.

Shriberg, L. D., Tomblin, J. B., \& McSweeny, J. L. (1999). Prevalence of speech delay in 6-year-old children and comorbidity with language impairment. Journal of Speech, Language, and Hearing Research, 42, 1461-1481.

Terband, H., Maassen, B., Guenther, F. H., \& Brumberg, J. (2014). Auditory-motor interactions in pediatric motor speech disorders: Neurocomputational modeling of disordered development. Journal of Communication Disorders, 47, 17-33.

Teverovsky, E. G., Bickel, J. O., \& Feldman, H. M. (2009). Functional characteristics of children diagnosed with childhood apraxia of speech. Disability and Rehabilitation, 31, 94-102.

Tilkens, C. M., Karlsson, H. B., Fourakis, M., Hall, S. D., Mabie, H. L, McSweeny, J. L., ... Shriberg, L. D. (2017). A diagnostic marker to discriminate childhood apraxia of speech (CAS) from Speech Delay (SD). (Technical Report No. 22). Retrieved 
from Phonology Project website: http://www.waisman.wisc. edu/phonology/

Tschida, K., \& Mooney, R. (2012). The role of auditory feedback in vocal learning and maintenance. Current Opinion in Neurobiology, 22, 320-327.

van der Merwe, A. (1997). A theoretical framework for the characterization of pathological speech sensorimotor control. In
M. R. McNeil (Ed.), Clinical management of sensorimotor speech disorders (pp. 1-25). New York: Thieme.

van der Merwe, A. (2009). A theoretical framework for the characterization of pathological speech sensorimotor control. In M. R. McNeil (Ed.), Clinical management of sensorimotor speech disorders (2nd ed., pp. 3-18). New York: Thieme. 